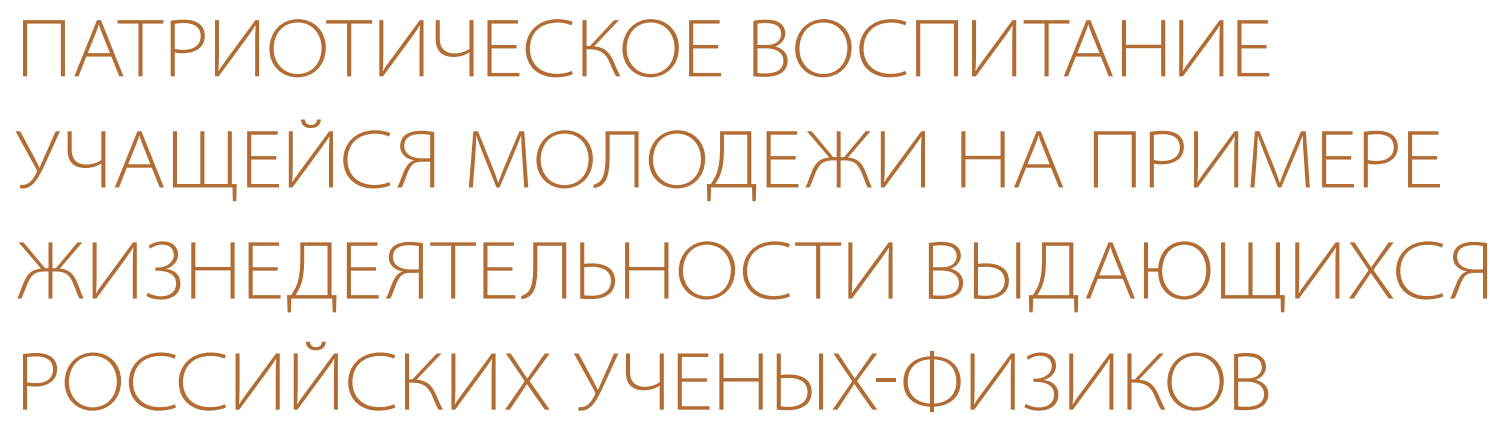

\title{
PATRIOTIC EDUCATION OF STUDENTS ON THE EXAMPLE OF THE LIFE OF OUTSTANDING RUSSIAN PHYSICISTS
}

\section{Овчаров Александр Владимирович}

Заведующий кафедрой технологических дисциплин, Алтайский государственный педагогический университет, доктор педагогических наук, профессор

E-mail: oav.ovcharov2010@yandex.ru

\section{Голубь Павел Дмитриевич}

Профессор кафедры физики и методики обучения физике, Алтайский государственный педагогический университет, кандидат физикоматематических наук

E-mail: golubpd@yandex.ru

\section{Аннотация. В статье представлен} материал, показывающий, как организовать патриотическое воспитание школьников и студентов на примере поступков и высказываний российских и советских ученых-физиков. Приводятся факты, свидетельствующие о глубокой любви многих ученых-физиков

\section{Ovcharov Alexander V.}

Head of the Department of Technological disciplines, Altai State Pedagogical University, ScD in Education, Full Professor

E-mail: oav.ovcharov2010@yandex.ru

\section{Golub Pavel D.}

Professor at the Department of Physics and Methods of Teaching Physics, Altai State Pedagogical University, PhD in Physics and Mathematics

E-mail:golubpd@yandex.ru

Abstract. The article presents the material showing how to organize Patriotic education of schoolchildren and university students on the example of actions and statements made by Russian and Soviet physicists. The facts testifying numerous Physicists' deep love for Russia - their homeland - are brought about.

() Овчаров А. В., Голубь П. Д., 2020 
к Родине - России. Рассмотрение темы начинается с деятельности первого российского академика М. В. Ломоносова, которая является ярким примером любви к Родине ученогопатриота. Приводятся аналогичные факты из жизни и научной деятельности российских электротехников В. В. Петрова, П. Л. Шиллинга, электротехников-изобретателей Б. С. Якоби, Э. Х. Ленца. Представлены исторические факты, свидетельствующие об истинном служении Родине ряда других ученых-физиков, включая, Ж. И. Алферова - известного во всем научном сообществе Нобелевского лауреата за работы в области современной физики.

Ключевые слова: патриотическое воспитание, физика, история физики.

\begin{abstract}
Consideration of the topic begins with the activities of the first Russian academician $M$. V. Lomonosov, which is a vivid example of the scientist-patriot's love for the Motherland. Similar facts from the life and scholarly endeavor of Russian electrical engineers $\mathrm{V}$. V. Petrov, P. L. Schilling, electrical engineersinventors B. S. Jacobi, E. H. Lenz are given. The historical facts testifying the true service to the Motherland by a number of other physicists, including Zh. I. Alferov - a Nobel laureate, known throughout the scientific community for his work in the field of modern physics.
\end{abstract}

Keyword: patriotic education, Physics, history of Physics.

В толковом словаре В. И. Даля слово «патриот» означает «любитель Отечества, ревнитель о благе его, отчизнолюб». Патриотизм, как качество личности, проявляется в любви к своему Отечеству, преданности, готовности служить своей Родине [1].

Понятно, что чувство патриотизма следует формировать еще с детского возраста. В последнее время правительством предпринимаются меры к возрождению патриотического воспитания. При этом основные надежды возлагаются на проверенного временем проводника патриотических идей в молодежную среду - школу. И действительно, это самый надежный путь становления как воспитательной работы в целом, так и воспитания патриотизма в частности.

Ранее через народную школу России красной нитью проходила философско-педагогическая позиция, заложенная одним из выдающихся педагогов К. Д. Ушинским: «Сделай как можно больше своему Отечеству». Эта идея настоятельно транслировалась в молодежную среду, понималась и принималась юношеством.

Естественно, что учителя не могут оставаться в стороне от намечающихся процессов, тем более что в ходе учебных занятий представляются широкие возможности для работы патриотической направленностис учащимися. Сейчас основной упор в такой работе делается на изучение материалов, связанных с периодом Великой Отечественной войны 1941-1945 гг., в которой наш народ ценой неимоверных усилий, мужества и огромных жертв сумел сломать хребет черным силам фашизма. В школах создаются военно-патриотические клубы, музеи, организуется забота и уход за памятниками, обелисками, военными мемориалами и братскими могилами, проводятся военно-патриотические игры. Изучаются биографии героев Великой Отечественной войны, ведутся поиски без вести пропавших воинов, особое внимание отводится оказанию шефской помощи живущим сегодня ветеранам Великой Отечественной войны. И это правильно. 
Однако существуют и другие возможности патриотического воспитания в школе, которые используются крайне недостаточно. Речь идет об успехах отечественной науки, в частности физики, на международной арене. Поскольку российская физическая наука начиналась в основном усилиями великого ученого-энциклопедиста Михаила Васильевича Ломоносова (1711-1765), то вполне логично изначально обратиться к его биографии и трудам. Перечитывая страницы жизнедеятельности Ломоносова, убеждаешься, что присущая истинно русскому человеку любовь к своим родным краям проявилась у него уже в раннем детстве. И в дальнейшем всю свою сознательную жизнь он видел основную задачу в борьбе за процветание так любимой им Отчизны.

В патриотической просветительской программе М. В. Ломоносова важное место отводилось получению научных знаний и их распространению. Борьба за это для него означала борьбу за высшее благо Родины. Известный литературный критик и видный просветитель Н. Г. Чернышевский писал: «Историческое каждого русского человека измеряется его заслугами Родине, его человеческое достоинство - силой его патриотизма... Ломоносов страстно любил науку, но думал и заботился исключительно о том, что нужно было для блага его Родины. Он хотел служить не чистой науке, а только Отечеству» [цит. по: 2, с. 48].

Став равноправным членом Российской академии наук, Михаил Васильевич вел непримиримую борьбу с засильем в ней иностранцев, многие из которых презирали все русское и пытались опорочить российскую науку и культуру. Ломоносов все свои помыслы и усилия направил на «приращение наук российских», он создал в стенах академии условия «иметь своих природных россиян в профессорах», чем удалось сломать сложившийся в то время стереотип, что природные россияне не способны к наукам. Деятельность Ломоносова в академии увенчалась небывалым успехом - к концу XVIII в. все ключевые места в ней заняли российские ученые. При этом исполнилась главная его мечта - деятельность академии теперь «простиралась к пользе и славе Отечества».

Смерть М. В. Ломоносова, к сожалению, прервала его патриотический порыв. Его предсмертные слова были наполнены думами о науке, думами о России: «Жаль только о том, что не мог я совершить всего того, что предпринял я для пользы Отечества, для приращения наук и для славы Академии».

В дальнейшем российская наука развивалась по пути, начертанному первым русским академиком, великим патриотом России М. В. Ломоносовым.

Особо следует отметить вклад российских ученых в становление и развитие электротехники. Многие их изобретения стали приоритетными на мировой арене. И как бы ни старались средства массовой информации Запада принизить роль россиян на этом поприще, выпячивая на передний план труды своих соотечественников, порой искажая суть дела, факты - вещь упрямая. А факты свидетельствуют о том, что основы практической электротехники заложены нашими отечественными изобретателями.

Когда ученые получили источник постоянного тока - вольтов столб, началось его интенсивное применение для проведения опытов и экспериментов. Первым, кто усовершенствовал этот прибор, стал профессор физики Петербургской медико-хирургической академии Василий Владимирович Петров (1761-1834). Исходя из идеи о том, что более интенсивный ток можно получить от более мощной батареи, он в 1802 г. сконструировал 
уникальный источник тока, дающий невиданное по тому времени напряжение - около 1700 вольт. С помощью этой батареи Петрову удалось впервые получить электрическую дугу, дающую мощное световое излучение и позволяющую резать металлы.

Характерно, что о своем открытии В. В. Петров сообщил в российском научном журнале на русском языке, хотя в то время было принято научные сообщения излагать на латыни [3]. Публикация его статьи была рассчитана на российского читателя, что свидетельствует о патриотизме ученого, сделавшего свое открытие достоянием России.

С открытием магнитного действия электрического тока в 1820 г. последовала целая серия изобретений таких устройств, которые оказались пригодными для практических нужд человека. И опять-таки лидирующие позиции в этом заняли электротехники из России. Так, в 1832 г. Павел Львович Шиллинг (1786-1837) предложил конструкцию телеграфа на электромагнитной основе. С помощью этого аппарата впервые в мире стала осуществляться телеграфная связь между Зимним Дворцом и зданием Министерства путей сообщения в Петербурге. Кстати, П. Л. Шиллинг, влекомый чувством патриотизма, стал активным участником Отечественной войны 1812 г., сражаясь в рядах 3-го Сумского гусарского полка. За проявленное мужество в боях он был награжден орденами и именной саблей «За храбрость» [3].

В мае 1834 г. российский электротехник-изобретатель Борис Семенович Якоби (18011874) создал первый в мире электродвигатель. По его выражению, «изобретение всякого нового двигателя... может рассматриваться не просто как любительское открытие, а как событие мирового значения». И такое событие свершилось усилиями самого Бориса Семеновича. В 1838 г. его электродвигатель с непрерывным вращением вала был применен на практике для приведения в движение лодки, которая с двенадцатью пассажирами двигалась по Неве со скоростью 2 км/ч.

В том же году Б. С. Якоби изобрел гальванопластику и многое сделал для внедрения ее в типографское и монетное дело, а также для производства художественных изделий. В дальнейшем гальванопластика широко использовалась при изготовлении скульптур для Исаакиевского собора. Свои патриотические чувства Б. С. Якоби выразил незадолго до смерти, написав: «Нижеподписавшийся гордится этой деятельностью потому, что она оказалась плодотворной в общем интересе человечества, вместе с тем принесла России непосредственную и существенную пользу» [3].

В первой половине XIX в. расцвел талант российского академика Эмилия Христиановича Ленца (1804-1865), который выразился в выдающихся научных достижениях его в области электромагнетизма. Для деятельности Э. Х. Ленца характерно редкое сочетание классного экспериментатора и вдумчивого теоретика. Так, на основе открытого закона для направления индукционного тока («правило Ленца») он сформулировал принцип обратимости электрических машин, а вскоре сам же и подтвердил его с помощью генератора, обращенного в электродвигатель.

Если вспомнить еще открытый Ленцем, независимо от Джоуля, закон теплового действия тока (закон Джоуля - Ленца), то уже этого достаточно, чтобы не без основания внести имя ученого в список основоположников электротехнической науки. Оставленное им научное наследие прочно вошло в практику исследований электротехников всего мира. Его 
разработки способствовали выходу российской науки и техники на уровень последних достижений того времени. О патриотизме Э. Х. Ленца его биографы писали: «...многочисленные ученики Ленца создали тот передовой отряд русских физиков, которые... прославили нашу Родину выдающимися открытиями».

1870-е гг. вошли в историю науки как начальный этап развития электроосвещения. И вновь на первых ролях в решении этой технической проблемы оказались российские изобретатели и конструкторы. Серьезным изобретением в области освещения было создание в 1872 г. электрической лампы накаливания, конструкцию которой предложил русский изобретатель Александр Николаевич Лодыгин (1847-1923). Уже через год он успешно демонстрировал освещение своими лампами одной из улиц Петербурга, проводил опыты по освещению ими предприятий, кораблей, домов.

В 1874 г. А. Н. Лодыгин получает патент на способ и аппараты электрического освещения. Его лампа накаливания была запатентована во многих странах, что и определяет приоритет российского изобретателя-электротехника в этом вопросе. На Венской электротехнической выставке лампы Лодыгина по всем параметрам превосходили появившиеся к тому времени зарубежные аналоги. За это изобретение А. Н. Лодыгин был награжден орденом Станислава 3-й степени, что еще раз подтвердило ведущие позиции российской науки и техники того периода.

Русский изобретатель Павел Николаевич Яблочков (1847-1894) в 1876 г. предложил новую оригинальную конструкцию электрической лампочки, работающей на переменном токе и получившей название «свеча Яблочкова». Изготовленные им фонари со свечами в виде огромных шаров были установлены на Оперной площади Парижа, на площади Этуаль и в других местах города. Парижане были в восторге от такого новшества, «Русское солнце!» - гласили заголовки газет. На свою систему «Русский свет» П. Н. Яблочков получил французский патент.

В дальнейшем поиски путей усовершенствования системы освещения привели его к изобретению трансформатора, а в цепях переменного тока он впервые использовал конденсатор. «Русский свет» засиял в помещениях, площадях и улицах Европы, Америки и даже Азии. Электрическое освещение, предложенное Яблочковым, распространилось по всему миру. Им освещались дворцы персидского шаха и короля Камбоджи.

Однако Павел Николаевич был истинно русским человеком и патриотом, все свои помыслы он связывал со своей Родиной. Преисполненный чувством патриотизма, Яблочков продал все свое имущество, а на вырученные средства выкупил у Франции свой патент и преподнес его в дар России [3].

Но не только физики и электротехники прославили российскую науку. В тот период весомое слово сказали и русские химики в лице Дмитрия Ивановича Менделеева (1834-1907). В 1869 г. он открыл один из фундаментальнейших законов естествознания Периодический закон химических элементов. Все химические элементы были расположены им в таблице по мере возрастания их атомных весов. Эта таблица и сам закон носят имя Менделеева.

Научный подвиг Дмитрия Ивановича принес отечественной науке мировое признание. Весь ученый мир оценил громадные заслуги русского ученого-химика. Он был 
избран членом Лондонской, Римской, Бельгийской, Парижской, Берлинской, Бостонской академиями наук. А в 1907 г. его фамилия значилась в списках кандидатов на Нобелевскую премию. К сожалению, Дмитрий Иванович скончался в том году, не дожив до получения столь высокой награды. Имя Д. И. Менделеева прочно вошло в анналы мировой науки, оно увековечено в названии одного из новых химических элементов под номером 101, который ныне называется «менделеевий», а 2019 год Организацией Объединенных Наций был объявлен годом Периодической системы химических элементов.

Горячо любивший Россию, Д. И. Менделеев много сил и времени отдавал изучению ее промышленности, сельского хозяйства и экономики. В конце своей жизни, как бы подводя итоги ее, он писал, «что первая служба его Родине - наука, вторая - народное образование, третья - промышленность». И на каждой из этих служб он проявлял себя не просто как талантливый ученый, но и как незаурядный государственный деятель [4].

Дмитрий Иванович был не только великим ученым, но и великим патриотом своей Родины, который видел и понимал будущее России лучше, чем многие представители власти. С болью в сердце он переживал военные поражения России в войне с Японией, когда сильно пострадала часть российского флота. Он заявлял, что «...если англичане вступят и в Кронштадт придут, и я пойду воевать». А ведь в то время ему исполнилось уже 70 лет.

На рубеже XIX-XX вв. наука преподнесла человечеству целый ряд важных открытий и изобретений. И в этом ситуации российские ученые оказались в самом центре событий. Так, в мае 1895 г. впервые в мире русский физик Александр Степанович Попов (1859-1905) осуществил радиосвязь с помощью сконструированного им прибора для обнаружения и регистрации электрических колебаний - радиоприемник. Уже вскоре проявилась практическая значимость данного радиоустройства. Оно было использовано для установления связи между севшим на камни в финском заливе броненосцем «Генерал-адмирал Апраксин» и берегом. При этом на протяжении четырех месяцев осуществлялась надежная радиосвязь на расстоянии в 52 км. Кроме того, в это же время с помощью радиограммы было передано сообщению ледоколу «Ермак» о терпящих бедствие рыбаках, унесенных на льдине в море. Благодаря этой телеграмме были спасены жизни 27 рыбаков.

Изобретение А. С. Попова дало толчок для быстрого развития радиосвязи во всем мире. Правительства передовых стран, правильно оценив возможности радиосвязи, щедро субсидировало работы по ее усовершенствованию. В 1897 г. (спустя два года после опытов Попова) итальянский инженер Г. Маркони получил английский патент на передачу телеграмм без проводов, чем оспаривал приоритет на изобретение радио. Эта проблема неоднократно решалась международными правительственными комиссиями. В настоящее время вопрос об изобретателе радио решен окончательно и однозначно - им является русский физик Александр Степанович Попов. Радио - это детище гения русского человека.

Важно подчеркнуть свойственное А. С. Попову стремление к практическому использованию знаний на благо людей, самозабвенную любовь к своей Родине и верность ей. Он не принял самых заманчивых предложений зарубежных фирм продать им патенты на свое изобретение. На поступающие ему предложения переехать за границу Александр Степанович неизменно отвечал: «Я русский человек, и все свои знания и весь свой труд я имею право отдать только моей Родине. И если не современники, то, может быть, потомки 
наши поймут, сколь велика моя преданность Родине и как счастлив я, что не за рубежом, а в России открыто новое средство связи».

В тот же период времени всему ученому миру стали известны уникальные опыты выдающегося русского физика-экспериментатора Петра Николаевича Лебедева (1866-1912) по измерению давления света. С помощью сконструированной им миниатюрной установки ему удалось измерить величину светового давления сначала на твердые тела (1899), а потом и на газы (1909). Уникальность его опытов состоит в том, что давление света настолько мало (примерно 0,4 миллиграмма на квадратный метр), что на результаты измерений влияют даже конвекционные потоки, радиометрический эффект и т. п. Лебедеву удалось остроумными и оригинальными способами устранить все помехи и ошеломить физиков Европы своими достижениями.

Первое сообщение о своих опытах он сделал в 1899 г. в Швейцарии, в 1900 г. выступил с докладом в Париже на Всемирном конгрессе физиков, а через год его работа была опубликована в немецком журнале «Annalen der Physik». Таким образом, об успехах русского ученого стало известно широкому кругу физиков разных стран. Результаты, полученные П. Н. Лебедевым, нашли самые восторженные отклики. Сам лорд Кельвин признавался: «Я всю жизнь воевал с Максвеллом, не признавая его светового давления, и вот ваш Лебедев заставил меня сдаться перед его опытом». А немецкий физик-спектроскопист Ф. Пашен так писал Лебедеву: «Я считаю Ваш результат одним из важнейших достижений физики за последние годы». Другой немецкий ученый В. Вин отметил: «Лебедев владел искусством экспериментирования в такой мере, в какой едва ли кто другой владеет в наше время».

Дальнейшему расцвету его экспериментаторского таланта помешали действия властей в Московском университете, когда из него ушли одновременно 124 профессора и сотрудника. Узнав, что Лебедев остался без работы, директор физико-химической лаборатории Нобелевского института в Стокгольме С. Аррениус предложил ему покинуть Россию и продолжить свою научную деятельность в Швеции. При этом ученому были обещаны прекрасно оборудованная лаборатория, необходимые средства для исследований и личных нужд и даже Нобелевская премия. Петр Николаевич, как истинный патриот России, не польстился на столь заманчивые предложения и отверг их.

В связи с переживаниями его за судьбу науки и Россию в целом его здоровье оказалось окончательно подорванным. В возрасте всего 46 лет П. Н. Лебедев скончался в 1912 г. Ученый мир с болью отреагировал на это трагическое событие. Так, известный во всем мире физиолог И. П. Павлов (Нобелевский лауреат 1904) с горечью восклицал: «Когда же Россия научится беречь своих выдающихся сынов - истинную опору Отечества?». Сегодня память об ученомпатриоте носит один из самых значительных научных центров современности - Физический институт академии наук (ФИАН), который чаще называют просто «институт Лебедева».

Далее можно привести немало примеров проявления патриотизма учеными России в советское время. Кстати, в тот период в СССР патриотическое воспитание молодежи осуществлялось должным образом в государственном масштабе. И это не могло не сказаться на деятельности ученых, стремящихся прославить Родину своими трудами.

Ярким представителем ученого-патриота с полным правом можно назвать Льва Давидовича Ландау (1908-1968). Его выдающиеся труды в различных областях физики были 
признаны всем мировым научным сообществом, а самого его выдвинули в число ведущих физиков-теоретиков мира. Апофеозом признания таланта Л. Д. Ландау стало присуждение ему в 1962 г. Нобелевской премии за теоретические исследования конденсированных систем и, в частности, за объяснение явления сверхтекучести гелия.

Льва Давидовича буквально засыпали приглашениями иностранные университеты для работы в них, на что он неизменно отвечал: «Нет! Я вернусь в свою страну, и мы создадим лучшую в мире науку». Действительно, ему удалось создать в СССР лучшую в мире школу физиков-теоретиков. Даже несмотря на то, что в годы репрессий он находился в заключении (1937-1938), Ландау оставался приверженцем социалистических идей, полагая, что «только у нас возможна популяризация настоящей нефальсифицированной науки для широчайших масс» [5]. Такая приверженность основывалась на чувстве высокой моральной ответственности за все происходящее в нашем обществе.

Физическая наука и в начале XXI столетия продолжала удивлять человечество новыми достижениями и открытиями. Здесь особо ценными с практической точки зрения оказались результаты исследований российского академика РАН Жореса Ивановича Алферова (1930-2019). На протяжении нескольких десятков лет он успешно занимался изучением гетероструктур, которые многими учеными считались неперспективными. Опровергнув такие мнения, Ж. И. Алферову удалось создать эффективные материалы, на базе которых им был разработан первый в мире полупроводниковый лазер на гетеропереходах с очень высоким КПД (порядка 50\%). Усилиями Жореса Ивановича в России впервые в мире было налажено производство гетероструктурных солнечных элементов для космических батарей, характеризующихся рекордно высокой эффективностью преобразования солнечной энергии в электрическую.

Академик Алферов, никогда не задумавшийся о личном комфорте, своими трудами сделал много для того, чтобы в новом веке человеку жилось еще комфортнее и удобнее. Разработанные им гетероструктурные материалы идут на изготовление лазерных диодов, компакт-дисков, электронных устройств для работы сотовой связи и Интернета, волоконно-оптической связи, приборов для считывания штрих-кодов. Понятно, что такие достижения не остаются без внимания мировой научной общественности, и в 2000 г. Жоресу Ивановичу Алферову была присуждена Нобелевская премия.

Ученый хорошо известен как человек, много сил и внимания отдававший привлечению в науку талантливой молодежи. Еще в 1970-е гг. им была организована работа школы «Физика и жизнь», где ежегодно проходили обучение от 30 до 40 наиболее одаренных школьников. В 1990-е гг. состоялось открытие научно-образовательного центра, в задачу которого входило выявление способных студентов, комплектование из них элитной группы для подготовки специалистов по особой программе. Конечную цель деятельности этого центра Алферов видел в предотвращении «утечки умов» за рубеж, так как массовый отъезд молодых талантливых ученых мог обескровить отечественную науку. Часть своей Нобелевской премии Жорес Иванович направил на поддержку созданной им школы для молодежи.

Ж. И. Алферов являлся депутатом Государственной Думы РФ, в которую пошел затем, чтобы избавить молодых ученых России от страшного выбора - потерять Родину 
(эмиграция в другие страны) или потерять себя (например, уйти из науки в бизнес, что в последние годы явление совсем не редкое).

Ж. И. Алферов был не только выдающимся ученым, педагогом и воспитателем научной молодежи, он - истинный патриот России. В своей книге «Физика и жизнь» он, в частности, подчеркивал: «Все, что создано человечеством, создано благодаря науке. И если уж нашей стране суждено быть великой державой, то она ей будет не благодаря ядерному оружию или западным инвестициям, не благодаря вере в Бога или Президента, а благодаря труду его народа, вере в знания, в науку, благодаря сохранению и развитию научного потенциала и образования [6].

Систематическое ознакомление учащихся с подобными материалами, как показывает практика, вызывает у них неподдельный интерес, а зачастую и удивление, поскольку в школьных учебниках ничего похожего они не встречают. И следует поклониться тому учителю, который на уроках изыскивает время, чтобы довести до учеников такие интересные и полезные в плане патриотического воспитания сведения.

Но ограничиваться краткой информацией об этом крайне недостаточно. Для популяризации материалов патриотического содержания можно и нужно шире использовать внеклассную работу: включать их в программу конференций, дней физики, проводимых в учебных заведениях, отмечать юбилейные даты крупных научных открытий и отдельных ученых, организовывать выпуски стенных газет и информационных бюллетеней. Школьники с удовольствием включаются в такую работу: готовя доклады по данной тематике, находят интересные факты в рекомендованных литературных источниках и Интернете, делятся новинками друг с другом и даже более заинтересованно относятся к изучению самой физики.

В итоге они проникаются чувством гордости за науку своей страны и за наших соотечественников - творцов физической науки. А все это, вместе взятое, способствует формированию патриотических убеждений у подрастающего поколения.

\section{Список литературы}

1. Даль В. И. Толковый словарь великорусского языка. М.: Дрофа, 2011. 510 с.

2. Крылова И. С., Каратунов В. М., Голубъ П. Д. М. В. Ломоносов - первый российский академик. Барнаул: КГБОУ, 2015. 57 с.

3. Голубъ П. Д., Оъчаров А. В., Насонов А. Д. Из жизни творцов физической науки. Барнаул: АлтГПУ, 2017. 359 с.

4. Менделеев Д. И. Заветные мысли. М.: Мысль, 1995. 413 с.

5. Бессараб М. Я. Так говорил Ландау. М.: Физматлит, 2004. 128 с.

6. Алферов Ж. И. Физика и жизнь. СПб.: Наука, 2001. 288 с.

\section{References}

1. Dal V. I. Tolkovyy slovar velikorusskogo yazyka. Moscow: Drofa, 2011. 510 p.

2. Krylova I. S., Karatunov V. M., Golub P. D. M. V. Lomonosov - pervyy rossiyskiy akademik. Barnaul: KGBOU, 2015. 57 p.

3. Golub P. D., Ovcharov A. V., Nasonov A. D. Iz zhizni tvortsov fizicheskoy nauki. Barnaul: AltGPU, 2017. 359 p. 
4. Mendeleev D. I. Zavetnye mysli. M.: Mysl, 1995. 413 p.

5. Bessarab M. Ya. Tak govoril Landau. M.: Fizmatlit, 2004. 128 p.

6. Alferov Zh. I. Fizika i zhizn. SPb.: Nauka, 2001. 288 p.

\section{Интернет-журнал \\ «Проблемы современного образования» \\ 2020, № 3}

Статья поступила в редакцию 24.10.2019

The article was received on 24.10 .2019 